\title{
Practical Use of the Eye Camera in Pedagogical Research (Processing of Selected Data Using the Eye Tracking Method)
}

\author{
Jana Škrabánková*
}

\begin{abstract}
The paper deals with author's pilot experiments using the eye tracking method for the primary school children examination. This method enables to gain a large amount of research data based on the tested people's eye movements monitoring. In the paper, there are processed chosen research data of four gifted students' examination in the context of their mathematical and logical intelligence.
\end{abstract}

Key words: eye tracking, research, mathematical and logical intelligence, gifted students.

\section{Introduction}

The Eye Tracker is a unique device used in many branches of the human activity - i.e. in advertisements and the estimate of its efficiency, in a marketing research, in a diagnostic of consumer's behaviour, readers of web pages, experimentally in medicine and it begins to be used in a pedagogical research and in cognitive science. The Eye Tracking is the term for the technology that enables to follow the movements of user's eyes at the screen, it enables to follow the exact place what the eyes are looking at in the course of time and also the way where the user's eyes are moving at the screen from one place to the other one. "Tracking of an eye with the eye camera enables to measure precisely the direction of the tested person. The system consists of two cameras - one of them scans the respondent's eye and the second one records his vision angle. Connection of both signals makes the output video where the direction of the tested person sight is possible to see and the moving red point shows the place of the sharp vision, which means the place what the respondent looks at. The advantage of the eye camera is in exact recording of the eye moving where (unlike the other technologies of the qualitative research) is no subjective impression of tested persons. That's why it is used in marketing research as well as for web page design, advertisements or TV spots. The other important part of the camera use are direct and indirect interactions of the human being with the

Jana Škrabánková, Department of Pedagogy and Andragogy, Faculty of Education, University of Ostrava, Ostrava, Czech Republic; jana.skrabankova@osu.cz 


\section{Acta Technologica Dubnicae \\ volume 6, 2016, issue 1}

computer. In the direct interaction, the eye camera replaces the input devices of the computer and it makes its control easy, mainly to handicapped people. During the indirect interaction, it serves as a diagnostic tool and the computer analyses the place of the eye fixation and it causes another action." (Rázek, 2008, p. 7)

\section{The Measurement Theory}

Jeroným Klimeš states that the eye tracking is always based on the combination of two information:

- Information of eyes or a head turning

- Information of a visual field of the human (Klimeš, 2008)

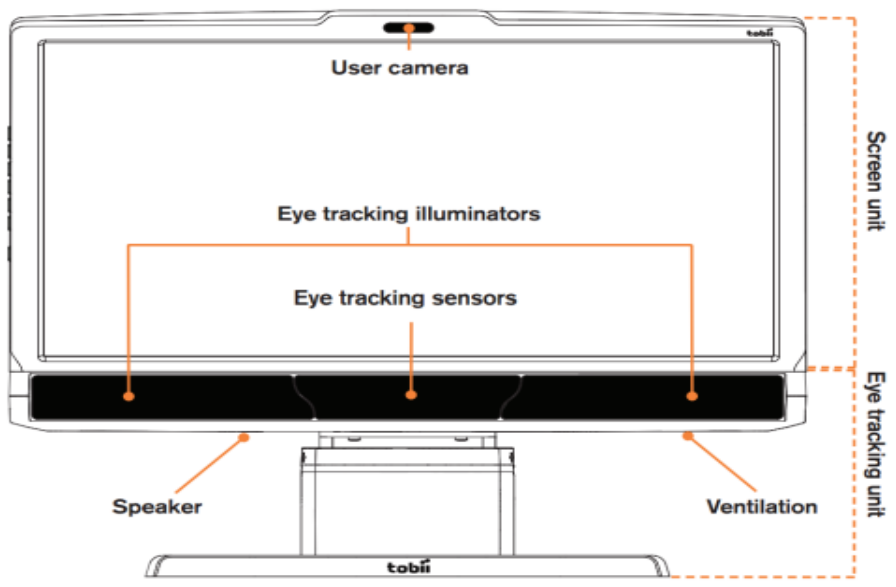

Figure 1. Device in the basic setting (Tobii Eye Tracker user manual, revision 2, page 24 - Front panel) (Jedlička, 2014).

The device records so called gaze patterns - sequential eye moving during reading the text, watching pictures or video etc. The movement is recorded as an eye fixation (circles) and saccades (lines among them). During saccades the eye doesn't catch any information. Thanks to individual fixations and added saccades among them, the device shows the progress of given picture(s) watching and we can do conclusions of it.

Typical use of the eye camera is the enter device position for computer programmes HCI (Human-Computer-Interaction). The example of the concrete application is i.e. writing using visual sense that is useful aid for users with certain type of handicap. 


\section{Content and Methods}

The Eye Tracking is possible to perceive as an instrumental and behavioural method. It shows exactly what the tested person does and not his/her opinion or ideas at the moment. "That's why it is mostly necessary to combine research using eye tracking and the other methods of questioning. The result of the research comes from three sources - see Fig. 2.” (Klimeš, 2008)

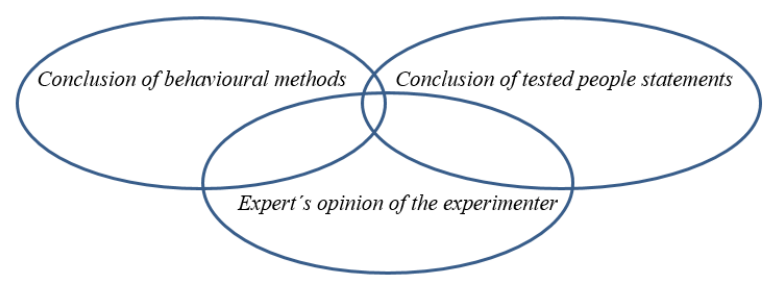

Figure 2. Sources of research results.

"Each of these methods brings mainly the information that is not possible to verify with other methods but some percent of all data can be confirmed. Similarly, even experience, attitude and opinion of the experimenter can influence the conclusion of the research very much." (Rázek, 2008, pg. 40). The author also writes: "That's why the experimenter is expected to be reasonable and to have his own consideration and evaluation of the tested material on the base of his previous experience and knowledge. His opinion is usually partly in collision with empiric data." (Rázek, 2008, pg.40).

The method that completes the classical Eye Tracking is a retrospective loud thinking. Ondřej Harink states: "There is a deep dialogue at the computer where runs a video of the given respondent's eyesight after the tested stimulus. The record includes even the record of the web camera that scans the face of the tested person during work with a stimulus material (web page /TV spot).

Everything is displayed at the same recording so that the respondent can see his/her eyesight and the face expression during all the time of the contact with the tested material. He/she can easily remember the reasons of his/her behaviour and also it is worse to stylize." (Herink, 2012)

"Eye tracking is possible to use in several levels:

- Simple observation how the human manipulates and works with presented materials from his point of view. There, it is possible to ignore the exact position of the sight and to keep an eye on individual behavioural operation: holding the post parcel, the way of opening the envelope, sequence of reading individual parts of the mail, the way of leafing through the manual or the instructions. Demands of such kind of observing can satisfy any miniature 


\section{Acta Technologica Dubnicae \\ volume 6, 2016, issue 1}

camera fastened at the head of the human but if we have an eye camera that enables this, we can use it even for this kind of work. Anyway this kind of observation enables to define questions and hypotheses that are specified in following phases.

- $\quad$ Simple observation of the human eyesight. This observation is focused on the point of sharp vision and the best is watching it in a slow-motion where and in what sequence the human examined given materials. Even, this way of the material observing serves mainly to a quantitative description: What saw this man? Why did he not understand some connection? Could he realize the intention of creators at this speed of browsing? Etc.

- $\quad$ Coding or other progress for evaluation of recordings. Various methods of coding enable to quantify a fluent flow for the eye behaviour. Results of coding enable to present an individual behaviour in transparent graphs and to abstract rules that are valid for the whole group. That's why coding will be included in the following chapter." (Klimeš, 2008)

\subsection{Methods Used for the Pilot Experiment}

- direct observing of gifted children

- dialogue

- coding method

- $\quad$ Eye Tracking method

In the pilot experiment, there was important how children proceeded during the text and picture observing. It was presented at the screen. And also there was important if they were able to solve related tasks and how they it did. For this study, I chose an analysis of just one assignment where I would like to show with the coding method and the analysis of pictures at the screen - the effects and the events that happened during solving at respondents. In the paper I rely on the fact that similar research of gifted children at the primary school in frame of their mathematical logical intelligence as an important part of natural science and mathematical talent still has not been done. During the choice of respondents, I proceeded from the Gardner Typology of Intelligence within the J. M. Havigerová conception. (Havigerová, 2011).

Logical mathematical dimension of intelligence includes understanding to numerical symbols and signs' meanings that are related to numerical operations. Above the world of senses, the pure abstract and logic are dominating (they are manifesting themselves very early, however, from the age of forty their productivity is subsiding).

The shows of talent in a given field:

- They like to count and they enjoy it.

- They put questions, for example "Where does the space finish?" "When did time start?" etc. 


\section{Acta Technologica Dubnicae \\ volume 6, 2016, issue 1}

- They like logical games, logical puzzles and riddles. They can do it for a long time.

- They prefer strategic games (i.e. chess) and they are very good at them.

- They like to do experiments to try things that are unknown to them.

For the pilot experiment, the respondents were chosen by the intentional choice. There were four children of the primary school at the age of seven to ten that they attend the Club of Gifted Children in the Moravian-Silesian Region. All these children are members of Mensa CR, they show a strong interest in mathematics and natural sciences and also their performance in this field is above average.

\subsection{Coding}

Coding consists in a definition of basic effects or events. In accordance with Klimeš, there is possible to understand the effect as a time section when the concrete searched behaviour is occurring and it make sense to speak about duration - the child has examined a given task for $\mathrm{x}$ seconds.

"Event means the time moment when a special behaviour occurred and there is no sense or it is not useful to speak about duration." (Klimeš, 2008). In example, in time 14:02-16:00 the tested child chose the answer. The important fact is that there was chosen the answer and there is not cardinal if the decision took 1 or 4 seconds. We record just the time of occurrence. (Time is usually written in a form of hh:mm:ss,ff where $\mathrm{H}$ is an hour, $\mathrm{M}$ is a minute, $\mathrm{S}$ is a second, $\mathrm{F}$ is a fraction of a second.)

Klimeš codes also so called absenting events (events that did not happen). This process is suitable when we want to have a complete knowledge of behaviour of the whole group. At these events, there is no need to speak neither about duration nor about time. We can have a code that signs: "The task was not been solved." Absenting events in the interpretation of my results are not used.

For the coding, we must have at least a video recording with a time code and a recorder.

Legend for the tabs:

Number of fixations...... number of duration at the effects; where the respondent stopped his sight

Total time................ total time when the respondent watched the given code repeatedly

$\operatorname{Max}$

the longest time when the respondent watched the given code 
Min the shortest time when the respondent watched the given code

The task assignment:

Find the size of the remaining angle, alternatively name it

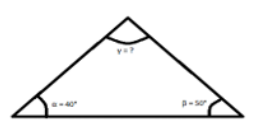

Notice: The sum of all angles in the triangle equals $180^{\circ}$

\section{Measuring results}

Table 1

Summary of codes - Jan

\begin{tabular}{|c|c|c|c|c|}
\hline$\frac{\text { Code / number }}{\text { of returns }}$ & $\frac{\text { Number of }}{\text { fixations }}$ & Total time (s) & Max. (s) & Min. (s) \\
\hline Assignment / 6x & 31 & 10,7 & 3,5 & 0,3 \\
\hline Triangle / $9 x$ & 72 & 24,9 & 10,1 & 0,4 \\
\hline Notice / 3x & 13 & 4,7 & 3,2 & 0,6 \\
\hline
\end{tabular}

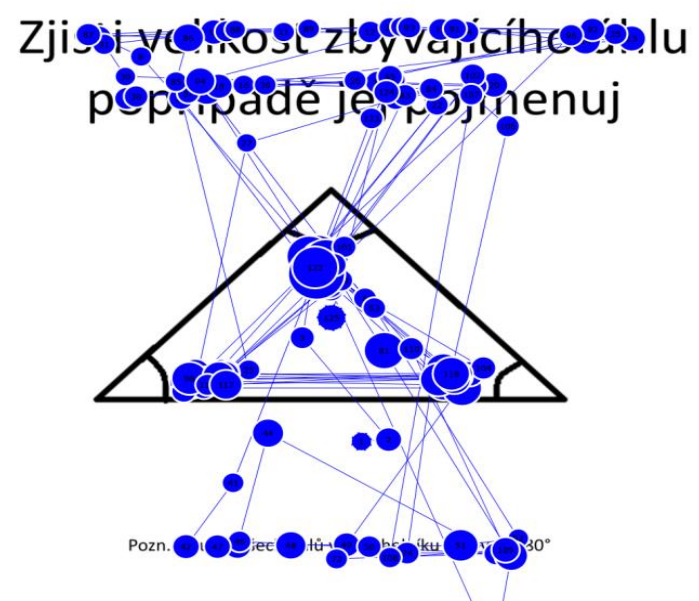

Figure 3. The eye track in last 0:43,486 seconds - Jan (Source: Author). 


\section{Acta Technologica Dubnicae \\ volume 6, 2016, issue 1}

\section{Conclusion}

The eye tracking is considered as one of possible parts of the quantitative research since the $19^{\text {th }}$ century. The ways of eyes watching are not by far new and they are possible to be divided into two groups. "One of them judges the eye position towards the head and the second one follows the eyes in the field or the target of the sight. Methods using the eye camera provide the eye position thanks to the interaction of the pupil's position and the reflection of the reference beam from the cornea. In combination with the scenic camera and unification of both recordings, the video arises. It roughly displays our visual angle and the exact point the sight is aiming." (Rázek, 2008, p. 81)

The pilot experiment uncovered a lot of areas that are possible to search. In our case, it should be i.e. the research of the time needed for the task solution depending on placing the Notice at the screen. The experiment proved that the children with mathematic and logical intelligence are able to solve tasks beyond their curriculum. The experiment also proved that these children are able to keep their attention during all the time of the task solving at their maximum and even their attention is increasing within the time necessary for the solution of difficult mathematical tasks. Repeatedly it is becoming apparent that there is necessary to create suitable educational methods and tools for the children with mathematical and logical intelligence development and it is necessary to support it in connection with the successful talent development.

In the end, it is important to mention that: “... contribution of testing by the eye camera can be partly distorted. We can learn what the sight is aiming at but we cannot explicitly exclude that the reader or the web visitor is thinking of something else all the time or if he understands all well." (Rázek, 2008, pg. 81). That's why it is necessary to fill in the Eye Tracking method with other suitable research practices - as I attempted in this paper.

\section{Acknowledgement}

Thanks to Libor Jedlička, the technician of the research Eye Tracking laboratory at the Faculty of Education, University of Ostrava, for the data export that was necessary for writing this paper.

\section{References}

Havigerová, J. M. (2011). Pět pohledi̊ na nadání. Praha: Grada Publishing. Hering, O. (2012). Co to znamená, když oči promluví? Trend marketing (Economia), 8(1), 34.

Kahneman, D. (2012). Myšlení - rychlé a pomalé. Brno: Jan Melvil publishing. 


\section{Acta Technologica Dubnicae \\ volume 6, 2016, issue 1}

Jedlička, L. (2014). Eye Tracker a Tobii Studio manual (ver.1. 2.). In Zeptejte se. Info. Retrieved from http://www.zeptejtese.Info/Tobii/Tobii_Studio_ Manual.pdf.

Klimeš, J. (2008). Využití oční kamery ve výzkumu reklamnich materiálů. Retrieved from http://www.sweb.cz/jeronym.klimes/ clanky/psychologie/ okkody/.

Rázek, Z. (2008). Oční kamera: teorie a praxe. Vysoká škola ekonomická $v$ Praze. Retrieved from http://www.vse.cz/vskp/5809_ocni_kamera_teorie _a_praxe. 